\title{
The need and implications of the human capital management system
}

\author{
Andreea Simina Porancea-Răulea ${ }^{1 *}$ \\ ${ }^{1}$ Lucian Blaga University of Sibiu, Sibiu, Romania
}

\begin{abstract}
In an era where technology and innovation seem to take over every organizational process, differentiation in terms of sustainable economic growth is achieved by implementing a human capital management system. In order to develop a proper model that encompasses a long-term perspective and an infinite organizational mindset, using a survey questionnaire collected data from 118 responses and 3 focus groups were conducted. This paper aims to highlight the results regarding the degree of implementation of the human capital management system and the implications for organizational performance arising from this approach. The results of this study present an evaluation model of human capital in organizations operating in the automotive field.
\end{abstract}

\section{Introduction}

The present is characterized by new industries that take over markets which no long ago did not exist. In addition, all is due to the constancy that bears the name of continuous change. In this context, the question arises of resisting and evolving from a competitive point of view. This is not an easy one to achieve because, for example, before technological capture and internet access the time of any intellectual capital transaction took place over a considerable period of time. Now, the exchange of information and implicit knowledge is carried out at a slow pace. The volume of data circulating is tangent with any domain and almost every corner of the world, which is why predictability and the factors that ensure continuity and success are quite difficult to identify.

But it is precisely the context in which information is available a click away from that facilitates the processing of information leading to verified models that can be applied in order to gain a competitive advantage.

Regardless of the field of activity, organizations have to anticipate change and meet consumers' needs and create the desire to buy more.

Organizations that have resisted over time have as a common point the malleability to change and adapt to the wishes of customers. In order to achieve this goal, the issues those organizations need to achieve in order to be sustainable must first be highlighted.

Sustainability is a concept that is a topical concern for the United Nations. Since 2015, 17 sustainable targets have been adopted by all member states relating to: economic growth,

\footnotetext{
*Corresponding author: andreea.raulea@ulbsibiu.ro
} 
access to basic services and resources, followed by biodiversity conservation, waste reuse, equality, inclusion and international cooperation.

From an organizational point of view, the sustainable development goals are pursued through indicator number eight which has as sub-indicators: achieving higher levels of productivity through diversification, technological modernization and innovation, including through a focus on sectors with added value and intensive use of labour, but also the promotion of policies that support productive activities, the creation of decent jobs, entrepreneurship, creativity and innovation, and encouraging formation and growth of micro, small and medium-sized enterprises.

Another sustainable development goal related to the subject of this article is the one assigned to indicator number nine. It concerns the development of a qualitative, reliable and sustainable infrastructure, the promotion of inclusive and sustainable industrialization and the strengthening of scientific research, the modernization of the technological capacities of industrial sectors.

So far few studies highlight a clear connection between the Sustainable Development Goals and organizational systems focused on human capital. But the data available from the European Statistical Institute can be analyzed.

Sustainable growth and decent jobs are important for the development and prosperity of European countries and for the prosperity of individuals. Economic growth must cover improvements in environmental efficiency, climate action. Sustainable economic growth also means generating job opportunities and improving working conditions for those already employed [1].

As regards the indicator that measures human resources in science and technology as a share of the working population in the 25-64 age group, there is an upward trend in Romania compared to the European average [2].

Looking forward to representative data, comparing the data presented by The European Innovation Scoreboard 2020, it is clear that Romania is among the few European countries to have recorded low values, well below the European average in terms of innovation performance.

Sales impacts and innovation-friendly environment and are the strongest innovation dimensions. Broadband penetration and medium and high-tech product exports are indicators close to EU average performance. The lowest indicators are: firm investments and human resources. Romania scores low at: lifelong learning, SMEs with product or process innovations, SMEs with marketing or organizational innovations, and SMEs innovating inhouse [3].

The above analysis sought to identify the link between the importance of implementing a human capital management system and the Sustainable Development Goals set out in the 2030 Agenda.

This parallel was drawn between sustainable development goals and innovation indicators in order to analyse if there is a close link between investment in research and development and the degree of sustainable development at both organisational and national or global level.

The conclusion from this data analysis is that meeting the sustainable objectives proposed by the United Nations Organization will implicitly lead to an increase in innovation performance indicators.

The scientific literature comprises studies about innovation, business competitiveness and sustainable growth. Within the studies taken into account were pointed out the role of innovation in organizational excellence.

By analyzing different excellence models (e.g. ISO 9000 family of standards, Malcom Baldridge model, and EFQM model) can be emphasized a correlation between innovation and the organization's performance, $80 \%$ of organizations deeming it even to be the key factor of success [4]. 


\section{The essence of the concept of human capital}

Innovation and sustainable progress are closely linked to adequate management of intellectual capital.

Although there are many opinions on the composition of intellectual capital this study refers to the composition comprising human capital, social capital, relational capital. More specifically, the focus is on the analysis of human capital in the context of sustainable development. For a linear analysis it is necessary to clarify terminology and to frame the temporal context of the concept.

Beginning with the end of the 20th century, intellectual capital was the star of social science research. Some researchers called intellectual capital "the main economic event of the late XX and early XXI centuries" [5]. The attention resides to these reasons:

-investments in intangible assets began to overperform investments in tangible assets [6] but this comes with the problem of predicting the value in long term transactions.

-organization management can create value, by identifying assets that count for innovation and development [7 - 9].

-non-financial management tools are more important than traditional ones.

-managing an organization by taking into account only financial resources is not enough.

These reasons led to new management tools as the Balanced Scorecard [10], Skandia Navigator ${ }^{\mathrm{TM}}$ [11] and others. These tools represent an attempt to assess the intellectual organization's capital, based on an indicators system that reflects the dynamics of intellectual capital components.

The competitive advantages of an organization relies on the resources exploitment in order to obtain a higher rate of return on investment. Thus codified knowledge becomes the success foundation. $[12,13]$. Currently, human capital becomes the most important factor for sustainable growth at organization level.

The XXth century concept of "land-labor-capital" transformed into "land-labor-capitalentrepreneurship-knowledge". Thus, knowledge began to generate the most value to the organizations. Knowledge is the key factor that generates benefit over a long period of time by ensuring a company's competitive edge. Knowledge, combined with the potential of human skills, competencies, ideas, professional experience is called the human intellectual capital [14].

Analyzing the literature it can be concluded that organisational return of investment is the result of technical progress, the quality of human, structural or relational capital and investments in research and development [15].

The measures needed to be taken into account in the event of the implementation of intellectual capital management should consider the efficient use of intellectual capital, finding coherent innovative solutions, reducing resource consumption and continuous improvement.

Previous studies have confirmed the correlation between intellectual capital and organisational performance [16 - 19].

Another relevant correlation for this topic is the link between innovation and the cycles of the economy identified by Schumpeter. According to him, two situations can be identified: the decrease in innovation activities during recession or a reverse development contrary to the economic cycle [20].

The major decrease in demand specific to the recession also implies a lower success rate of an innovative product. A source of constraint or a generator of innovation opportunities for organisations is the National Innovation System which manages the stabilisation of R\&D investments [21]. 
A different perspective on optimal decision-making in the innovation process is that it is at its highest level immediately before or after a technological breakthrough [22].

\section{CASE STUDY}

To determine how a human capital management system as a representative component of intellectual capital influences the performance of an organisation, we conducted a questionnaire and focus group analysis.

The questionnaire was sent to middle management managers from the human resources, financial and development departments. The questions were related to the components of intellectual capital and how are they managed within the organization.

Building on the above-mentioned international premises and studies, the purpose of the research was to analyse the degree of implementation and how a human capital management system influences organisational performance.

With regard to the need to implement an intellectual capital quality management system, the focus group participants and respondents, most of them human resources managers, unanimously agreed on the usefulness and positive results that could occur. Although in each organisation in which research participants work they have implemented aspects that also measure certain components of what is called generic intellectual capital, they consider that they are not sufficient.

A complex system for measuring each component, reflecting an overview of organisations is required. Another problem is the uniformity of measurement and subsequent reporting systems so that relevant comparisons can be made. This need is useful from a competitive and commercial point of view.

Regarding the indicators on which the study participants agreed are the following: the working environment, the resistance to new ideas, the existence of creative stimulation efforts, the number of hours devoted to training, the quality of training programmes, the average development time of new products, leadership skills.

Each of these indicators assigned a measurement scale as follows.

I1. Working environment: hostile, demanding, stressful, pleasant, stimulating.

I2. Resistance to new ideas: null, low, medium, high, very high resistance.

I3. Creative efforts: existing, non-existent.

I4. Number of hours dedicated to training: 0, 80, 160, over 160.

I5. Quality of training programs: poor quality, qualitative, non-qualitative.

I6. Average development time of new products: half a year, a year, more than a year.

I7. Leadership skills: existing, non-existent.

Thus, the human capital quality index is in the form: $\mathrm{I} 1 * 5 \%+\mathrm{I} 2 * 5 \%+\mathrm{I} 3 * 10 \%+\mathrm{I} 4 * 10 \%+\mathrm{I} 5 * 15 \%+\mathrm{I} 6 * 30 \%+\mathrm{I} 7 * 25 \%$

Depending on the value of this indicator, improvement measures will or will not be taken. Although the composition of this indicator may seem simplistic, the study participants, through the lens of experience, concluded that it is a starting point in terms of a broad evaluation.

A confirmation of the results of this analysis comes from the results presented in the IMD World Digital Competitiveness Ranking for Romania.

Analyzing this report in which at national level we rank 49th out of 63 countries, reinforces the idea proposed by the study participants regarding the need to implement a human capital management system. 


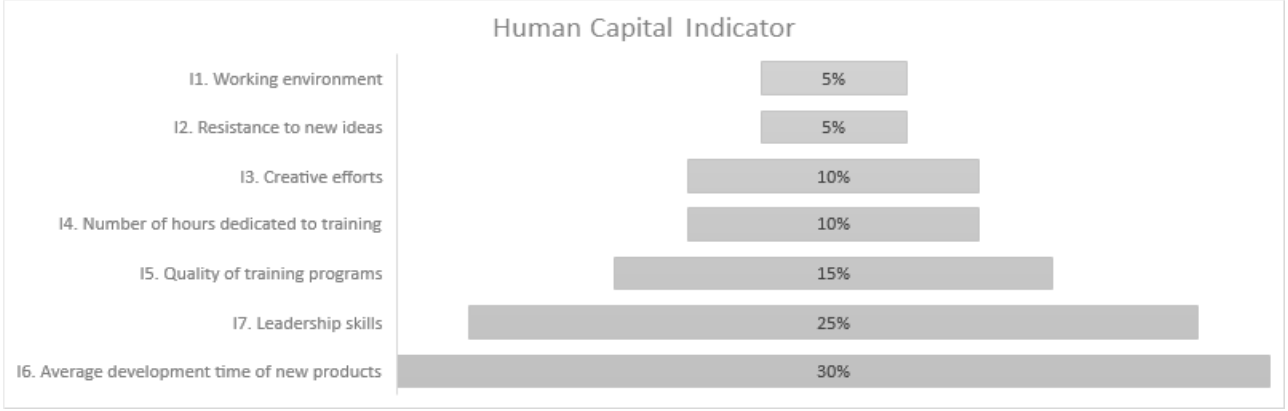

Fig. 1. Human Capital piramid indicator

The figure below shows a selection of indicators directly connected to the subject of the research. One of the indicators at which Romania scored the lowest is the one that quantifies technological/digital skills. This has a great deal of organisational implications when the implementation of innovative technologies is called into question. In practice, it is obvious from this report that Romania, as a whole, is not ready to implement innovative technologies because these skills are lacking on a human level.

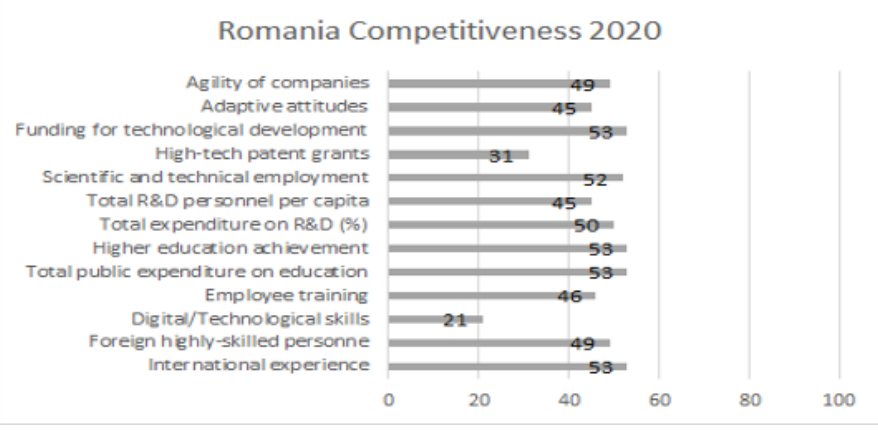

Fig. 2. Romanian Competitiveness 2020.

Another issue that leads Romania to its last positions is the grants awarded to patents.

Bearing in mind the analogy in which a research grant represents a collaboration between at least two entities from the score highlighted, there are at least two problems: the lack of collaboration between entities with similar concerns and the small number of patents in the field of high tech technology. As can be seen from the analysis from the data extracted from the report by the World Intellectual Property Organization [23], Romania recorded a number with a significant annual decrease rate. This is a negative factor when it comes to external investment.

The adaptability of employees and the organisation's inclusion as agile are two other factors that highlight the need for measures to improve the quality of human capital. But for this to occur, a measurement system must be implemented first.

The score obtained for public expenditure on education, employee training and educational achievements are indicators that reinforce the need to change the approach of human capital. Starting from the time of -1 when employees are still enrolled in the education system, an analysis of the needs from the point of view of employers is required. 


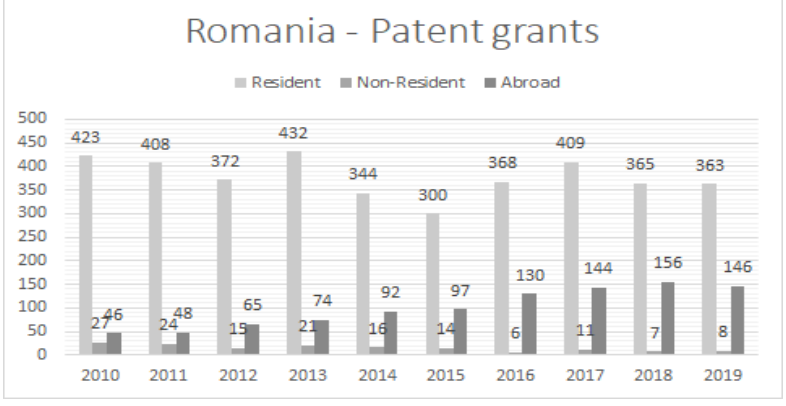

Fig. 3. Romania - patent grants evolution

By facilitating the communication of needs, a system can be implemented to build on knowledge. In order to measure how organisations are involved in the social-educational context, I propose the insertion of an additional indicator to measure the degree to which organisations facilitate internships and the number of hirings that arise from them. Another important aspect is how organisations work with universities.

\section{CONCLUSIONS}

The conclusions of the research carried out at the local level, compared to the results presented at national level in the IMD World Digital Competitiveness Ranking [24] confirm the need to implement a human capital management system.

It is estimated that in the future the value of the employees will be the leadership skills. Since now, major organizations have reported substantial challenges in finding employees with both technological background and strategic economic thinking. In this respect, resolution must come primarily from academia that should adapt the curriculum and promote multidisciplinary learning. Second, organisations should promote peer-to-peer training and stimulate the accumulation of knowledge on an ongoing basis.

The evaluation and setting of human capital improvement targets are the goals that organisations should set annually. It is important to standardise those indicators considered relevant to the external environment, but the heterogeneity of organisations must also be taken into account. Depending on the scope of the activity, the indicators may differ substantially and the weights associated with each change.

In the context of sustainable development, the first element that should be systematized is human capital. It is the knowledge embedded in human capital that can make a long-term difference in decision-making. The more we invest in human capital, the more improvements will be seen in the other components. Although it is assumed that the future will belong to robots, it should be borne in mind that at the organizational level the implementation of such solutions can only be done by the human resource that fully understands the advantages and can calculate the financial benefits. There are countless commercial failures that have occurred because of the resistance to change that decision-makers have had. In order not to reach that point, organisations must implement a human capital management system that is quality-oriented and adaptable. The constant accumulation of knowledge should be the focus of any entity with long-term success.

Although the literature does not yet provide a clear evaluation system from this perspective, a first step could be the implementation of a system based on the indicators mentioned in this study. These indicators are a first brick in what will be called a human capital assessment system that organisations will also implement in the near future.

Globally, a human capital index has already been adopted, now it is the turn of organisations to do so. 


\section{References}

1. European Commission. Employment and Social Developments in Europe. Luxembourg, (2019)

2. Eurostat Database. Science Technology and Innovation.(2020)

3. European Innovation Scoreboard. (2020)

4. R. Jankal, The role of innovation in the assessment of the excellence of enterprise subjects. Jankal, Social and Behavioral Sciences 109 (2014)

5. B. Lev, Intangible Assets: Concepts and Measurements. New York, Elsevier, Encyclopedia of Social Measurement (2005)

6. B. Lev, S. Radhakrishnan, The Measurement of Firm-Specific Organization Capital. Cambridge: National Bureau Of Economic Research (2003)

7. J. Stern, B. Stewart, D. Chew, The EVA Financial Management System: Journal of Applied Corporate Finance (1998)

8. Rappaport, Creating Shareholder Value: The New Standard for Business Performance. New Yotk: Free Press (1986)

9. S. Young, S. O’Byrne, EVA and Value Based Management: A Practical Guide to Implementation. McGraw-Hill Professional Publishing (2001)

10. R. Kaplan, D. Norton, D. Boston, The Balanced Scorecard: Translating Strategy into Action.: Harvard Business School Press (1996)

11. L. Edvinsson, M. Malone, Intellectual Capital: Realizing Your Company's True Value by Finding Its Hidden Brainpower. New York: HarperCollins Publishers (1997)

12. C. Prahalad, G. Hamel, The Core Competence of Corporation: Harvard Business Review, pp. 275-292 (2006)

13. D.J. Teece, G. Pisano, A. Shuen,. Dynamic capabilities and strategic management. Strategic Management Journal 18, 7 (1997)

14. Manifestation of Intellectual Capital in Trade During Period 2008 - 2018. Nikolova, I. 3, s.1. Economic Alternatives (2019)

15. A. Seleim, A. Ashour, N. Bontis, Intellectual capital in Egyptian software firms: s.n., The Learning Organization (2004)

16. N. Bontis, W. Chua Chong Keow, S. Richardson, Intellectual capital and business performance in Malaysian industries s.l.: Journal of intellectual capital 1 (2000)

17. M. Cabrita, N. Bontis, Intellectual capital and business performance in the Portuguese banking industry, s.l.: International Journal of Technology Management 43 (2008)

18. 18.A. Sharabati, S. Naji, N. Jawad, Bontis Intellectual capital and business performance in the pharmaceutical sector of Jordan,. Management decision 48 (2010)

19. A. Seleim, A. Ashour, N. Bontis, Intellectual capital in Egyptian software firms,. s.l.: The Learning Organization 11 (2004)

20. A. Filippetti, D. Archibugi, Innovation in times of crisis: National Systems of Innovation, structure and demand,.s.l.: Research Policy 40 (2011)

21. C. Paunov, The Global crisis and firms investments in innovation, s.l.:Research Policy 41 (2012)

22. N. Hritonenko, Y. Yatsenko,. s.l. Technological innovations, economic renovation, and anticipation effects: Journal of Mathematical Economics 4 (2010)

23. World Intellectual Property Indicators 2020. Switzerland (2020)

24. IMD World Digital Competitiveness Ranking (2020) 